Revista Brasileira de Agricultura Irrigada v.12, nº.3, p. 2644 - 2652, 2018

ISSN 1982-7679 (On-line)

Fortaleza, CE, INOVAGRI - http://www.inovagri.org.br

DOI: $10.7127 /$ rbai.v12n300814

Protocolo 814.18 - 13/11/2017 Aprovado em 29/05/2018

\title{
EFICIÊNCIA DE USO DA ÁGUA NA IRRIGAÇÃO COM DÉFICIT NA MELANCIEIRA, UTILIZANDO O MODELO ISAREG
}

\author{
Kleiton Rocha Saraiva ${ }^{1}$, Thales Vinícius de Araújo Viana², Solerne Caminha Costa ${ }^{3}$, \\ Francisco Marcus Lima Bezerra ${ }^{4}$, Raimundo Reginaldo da Costa ${ }^{5}$, Cley Anderson Silva de \\ Freitas $^{6}$
}

\section{RESUMO}

Objetivou-se comparar as proposições de irrigação geradas a partir do ISAREG com o manejo de irrigação modal, adotado pelos irrigantes, avaliando e analisando a produtividade da cultura da melancia e a eficiência de uso da água, sob as diferentes proposições de irrigação e condições de cobertura do solo; e, os efeitos da interação das variáveis. Os experimentos foram conduzidos sob delineamento em blocos completos ao acaso, com parcelas subdivididas e com 4 repetições. Os tratamentos consistiram da combinação de 04 proposições de irrigação (três proposições do ISAREG: M1 = manutenção de $100 \%$ da CAD; M2 de 80\% e M3 de 60\%; e M4, lâmina modal) e 04 sub-parcelas, sendo 03 condições de cobertura no solo (coberturas com casca de arroz, com "mulching" branco e com "mulching" preto, denominadas C1, C2 e C3), e a sub-parcela 4, o solo sem cobertura (C0). Foram analisadas a produtividade e a eficiência de uso da água. Os resultados foram submetidos à análise de variância, e quando significativos, à análise de regressão, a teste de médias e a gráficos de tendência. Concluiu-se que, em geral, MIC1 e M1C2 demonstraram as maiores produtividades; a maior eficiência de uso da água foi verificada em M3C2 e a menor em M4C0.

Palavras-Chave: irrigação deficitária, software, Citrullus lanatus, convivência com o semiárido

\section{WATER USE EFFICIENCY IN IRRIGATION DEFICIT IN WATERMELON, USING THE MODEL ISAREG}

\footnotetext{
ABSTRACT

This study aimed to compare the irrigation propositions generated from ISAREG with handling modal irrigation, adopted by irrigators, evaluating and analyzing the watermelon

${ }^{1}$ Doutor em Engenharia Agrícola. Instituto Federal do Piauí - IFPI. E-mail: kleiton.rocha@ifpi.edu.br

${ }^{2}$ Doutor em Irrigação e Drenagem. Universidade Federal do Ceará - UFC. E-mail: thales@ufc.br

${ }^{3}$ Doutor em Engenharia Agrícola. Instituto Federal do Ceará - IFCE. E-mail: solernecosta@gmail.com

${ }^{4}$ Doutor em Irrigação e Drenagem. Universidade Federal do Ceará - UFC. E-mail: mbezerra@ufc.br

${ }^{5}$ Tecnólogo em Irrigação. Instituto Federal do Ceará - IFCE. E-mail: regis_dacosta@yahoo.com.br

${ }^{6}$ Doutor em Engenharia Agrícola. Instituto Federal do Ceará - IFCE. E-mail: cleyanderson@ifce.edu.br
} 
crop productivity and efficiency of water use under different propositions irrigation and conditions ground cover; and the effect of interaction between variables. The experiments were conducted under design in randomized complete block design with split plots and four repetitions. The treatments consisted of the combination of 04 irrigation propositions (three propositions of ISAREG M1 = maintaining 100\% of CAD; M2 80\% and M3 60\% and M4, modal blade) and 04 sub-plots, with 03 conditions cover the soil (covers with rice husk with "mulching" white and "mulching" black, called C1, C2 and C3), and the sub-plot 4, the bare soil (C0). productivity and efficiency of water use were analyzed. The results were submitted to analysis of variance, and when significant, the regression analysis, the mean test and trend graphs. It was concluded that, in general, MIC1 and M1C2 showed the highest yields; the largest water use efficiency was observed in M3C2 and the lowest in M4C0.

Keywords: deficit irrigation, software, Citrullus lanatus, coexistence with the semiarid

\section{INTRODUÇÃO}

Uma crescente escassez de água devido ao aumento populacional e ao desenvolvimento econômico está ampliando os desafios para a agricultura, perdulária no seu uso, necessitando-se que se encontrem novas soluções para a gestão dos recursos hídricos, principalmente onde a água é limitada. A população do semiárido tem convivido com períodos de seca prolongada que afetam as atividades agropecuárias e dificultam a melhoria das condições de vida (PEREIRA; CUELLAR, 2015).

Além disso, no semiárido do Nordeste do Brasil predominantemente ainda não se realiza o correto manejo da irrigação. Como resultado, além das baixas produtividades, normalmente se aplica mais água do que as culturas necessitam.

Uma das alternativas para se evitar o desperdício do recurso hídrico é a utilização de softwares usados no manejo da irrigação que calculam os requerimentos de água a partir de dados do clima, do solo e da cultura (PEREIRA, 2004). Como exemplo, tem-se o modelo ISAREG, desenvolvido no Instituto Superior de Agronomia, em Portugal.

Outra maneira de se reduzir o uso do recurso hídrico na agricultura é através da utilização de cobertura no solo, que é uma tecnologia simples e cujos benefícios sobre a produtividade das culturas são irrefutáveis. Inclusive, vários pesquisadores vêm investigando os efeitos das coberturas sob a produção de várias culturas (DANTAS et al.,
2011; SANTOS et al., 2012). Além disso, a interação entre estas tecnologias pode possibilitar aumento da produtividade agrícola com redução de uso do recurso hídrico.

A pesquisa objetivou comparar as proposições de irrigação geradas a partir do ISAREG com o manejo de irrigação modal, atualmente, adotado pelos irrigantes do DIJA, avaliando e analisando a produtividade da cultura da melancia e a eficiência de uso da água, sob as diferentes proposições de irrigação e condições de cobertura do solo; e, os efeitos dessa interação na economia do recurso hídrico.

\section{MATERIAL E MÉTODOS}

A pesquisa foi realizada na UEPE (Unidade de Ensino, Pesquisa e Extensão) do Instituto Federal de Educação, Ciência e Tecnologia - IFCE, em Limoeiro do NorteCeará (0506’38” S; 37052’21” W; 145,95 m), no Distrito de irrigação Jaguaribe - Apodi, DIJA. O clima local é do tipo BSw’h', semiárido, segundo a classificação climática de Köppen (1981-2005, DNOCS).

Durante o processo de simulação do "software ISAREG", o mesmo foi "alimentado" com dados oriundos de pesquisas locais, das seguintes variáveis: dados físicos do solo; fases fenológicas da cultura, bem definidas; fator de disponibilidade de água (f) e profundidade efetiva do sistema radicular ( $\mathrm{Z}$ ), ambas a cada 
fase fenológica. Também, o modelo necessitou de dados sobre o manejo da irrigação, em que 3 (três) foram calculados pelo ISAREG (Irrigação com déficit - 60\%, $80 \%$ e $100 \%$ da CAD) e o outro constou da lâmina média de $6,3 \mathrm{~mm}$ dia $^{-1}$, durante o ciclo da melancia, praticada pelo irrigante do DIJA.

Realizou-se o experimento, sob delineamento em blocos completos ao acaso, com parcelas subdivididas e com 4 repetições ( $4 \times 4 \times 4$, totalizando 64 sub-parcelas). Os tratamentos consistiram da combinação de 04 proposições de irrigação (três proposições do ISAREG e o manejo modal dos produtores denominadas M1, M2, M3 e M4), que constituíram as parcelas, e 04 sub-parcelas, sendo 03 condições de cobertura do solo (com casca de arroz, com "mulching” branco e com "mulching” preto, denominadas C1, C2 e C3), e a sub-parcela 4, o solo sem cobertura (testemunha), denominado C0.

As proposições do ISAREG foram: M1, o manejo ótimo de irrigação (lâmina proposta para a manutenção diária do solo na sua capacidade máxima de armazenamento, 100\% da CAD, sem percolação, para um solo sem cobertura); M2, proposição de lâmina diária para manutenção do armazenamento de água do solo, sem cobertura, em torno de $80 \%$ da CAD; M3, proposição de lâmina diária para manutenção do armazenamento do solo sem cobertura, em torno de $60 \%$ da CAD; e o tratamento M4 representou a lâmina modal diária utilizada pelos irrigantes locais.

A cultura foi plantada no espaçamento 2,0 $\mathrm{m} \times 0,5 \mathrm{~m}$, sendo que cada sub-parcela consistiu de 6 plantas, perfazendo $6,0 \mathrm{~m}^{2}$ (2,0 $\mathrm{m} \times 3,0 \mathrm{~m})$. A área onde foram feitas as determinações (área útil por sub-parcela) compreendeu a área ocupada pelas 4 plantas do centro da fileira. Houve uma linha de bordadura entre as linhas com tratamento, perfazendo nove linhas $(9 \times 2,0 \mathrm{~m}=18,0 \mathrm{~m}$ de largura). Cada bloco teve quatro subparcelas por tratamento, perfazendo $216,0 \mathrm{~m}^{2}$ $(18,0 \mathrm{~m} \times 12,0 \mathrm{~m})$. A área total do experimento foi de 864,0 $\mathrm{m}^{2}$ (18,0 $\mathrm{m} \mathrm{x} 48,0$ $\mathrm{m})$.

A semeadura foi realizada em bandejas de isopor, com 128 células, com substrato comercial, isso de acordo com o número necessário de plantas que precisaram ser transplantadas. Já o transplante ocorreu sete dias após a semeadura.

De acordo com os resultados das análises de solo foram recomendadas as quantidades dos adubos químicos, visando suprir as necessidades da cultura, em macro e micronutrientes. No entanto, para a determinação da frequência de aplicação da fertirrigação, tomou-se como base a pesquisa realizada por Fernandes et al. (2014). Os adubos foram aplicados via fertirrigação, iniciando-se no dia do transplantio e finalizando-se aos 50 DAT (dias após o transplantio). Os produtos comerciais utilizados foram uréia $(\mathrm{N})$, cloreto de potássio branco $\left(\mathrm{K}_{2} \mathrm{O}\right)$, ácido fosfórico $\left(\mathrm{P}_{2} \mathrm{O}_{5}\right)$, sulfato de enxofre (S) e ácido bórico (B).

A colheita foi realizada quando os frutos atingiram o ponto de maturação fisiológica, com ${ }^{\circ}$ Brix mínimo em torno de $8^{\circ}$, determinado em campo com refratômetro portátil. As colheitas periódicas foram feitas em intervalo de cinco dias, tendo inicio aos 67 DAT. Foram realizadas 2 colheitas, tendo sido considerados frutos comerciais aqueles com peso acima de $0,80 \mathrm{~kg}$, formato normal e não estragados.

A cultura foi irrigada por um sistema localizado, tipo gotejamento, com uma linha de gotejadores por fileira de plantas. Os gotejadores foram do tipo autocompensante, com vazão média de $2,3 \mathrm{~L} \mathrm{~h}^{-1}$, para uma pressão de serviço de $300 \mathrm{kPa}$. As irrigações foram realizadas diariamente, durante todo o ciclo da melancia.

As quantidades diárias de água aplicadas seguiram as proposições de irrigação (Li) elaboradas através do ISAREG e o manejo modal adotado pelos irrigantes do DIJA, conforme os tratamentos adotados. Os dados de evapotranspiração da cultura (ETc) fornecido ao modelo foram obtidos através de experimentos locais, pela metodologia do balanço hídrico no solo; e a ETo foi estimada por Penman - Monteith/FAO, descrita por Allen et al. (1998), com dados de varáveis climatológicas locais. O coeficiente cultural 
(Kc) foi obtido pela razão entre as duas variáveis supracitadas.

O tempo de irrigação utilizado diariamente foi calculado a partir da lâmina de irrigação proposta para cada tratamento, em conformidade com a equação 1 .

$$
\mathrm{Ti}=\frac{L_{I} * E_{L} * E_{g} * F_{C}}{E i * q_{g}}
$$

em que,

Ti é o tempo de irrigação, em h; Li é a lâmina de irrigação proposta no tratamento i pelo ISAREG; El é o espaçamento entre linhas de irrigação, 2,0 m; EG é o espaçamento entre gotejadores, $0,5 \mathrm{~m}$; FC é o fator de cobertura do solo, adimensional; Ei, é a eficiência de irrigação, adimensional $(0,95) ; q_{g}$, é a vazão do gotejador $\left(2,3 \mathrm{~L} \mathrm{~h}^{-1}\right)$.

Para a utilização do fator de cobertura (Fc) do ciclo da melancia, que representa a relação entre a área molhada e a área ocupada pela cultura, seguiu-se a recomendação de Bernardo et al. (2008), quando o mesmo afirmou que o Fc deve ser de no mínimo 33\% $(0,33)$ quando se trata de regiões áridas e semiáridas. Também, foram utilizados os resultados de Miranda et al. (2004).

Quanto às coberturas, em um dos tratamentos (C1), utilizou-se a casca de arroz, que é bastante abundante na região. A cobertura apresentou cerca de $2 \mathrm{~cm}$ de altura, com área de $0,5 \mathrm{~m}^{2}$ em torno da planta, perfazendo aproximadamente 10 litros por planta.

As seguintes variáveis foram analisadas: a produtividade média, que foi obtida através da função entre o peso médio dos frutos, o número de frutos por planta e a área do experimento $\left(864 \mathrm{~m}^{2}\right)$, com posterior extrapolação para a área de $10.000 \mathrm{~m}^{2}$ (1ha).

A eficiência de uso da água (EUA) foi determinada pela relação entre produtividade e lâmina de água, para cada tratamento (equação 2).

$$
E U A=\frac{\text { Pr odutividade da cultura }\left(\mathrm{kg} \mathrm{ha}^{-1}\right)}{\operatorname{lâ} \min a(\mathrm{~mm})}
$$

onde:

EUA: Eficiência no uso da água $\left(\mathrm{kg} \mathrm{ha}^{-1} \mathrm{~mm}^{-}\right.$ ${ }^{1}$ );

Produtividade da cultura: ( $\left.\mathrm{kg} \mathrm{ha}^{-1}\right)$;

Lâmina de água utilizada: (mm).

Os dados resultantes das características analisadas e suas interações foram submetidos à análise de variância; quando significativos pelo teste $\mathrm{F}$, os dados foram submetidos ao teste de médias de Tukey, a $1 \%(* *)$ e $5 \%\left(^{*}\right)$ de probabilidade. Ademais foram elaborados gráficos de tendência (interação entre os fatores).

\section{RESULTADOS E DISCUSSÃO}

Quanto à produtividade média, a partir da análise de variância (Tabela 1) foi verificado efeito significativo $(p<0,01)$ para a interação entre lâminas de irrigação versus coberturas no solo, para as seguintes variáveis analisadas: produtividade média e eficiência de uso da água.

Tabela 1. Resumo da análise de variância e níveis de significância para as variáveis: produtividade média (PM) e eficiência de uso da água (EUA)

\begin{tabular}{lccc}
\hline \multicolumn{1}{c}{ FV } & GL & \multicolumn{2}{c}{ Quadrado Médio } \\
\cline { 3 - 4 } & & PM & EUA \\
\hline Lâminas de Irrigação (LI) & 3 & $511,02042^{* *}$ & $174911,36139^{* *}$ \\
Resíduo (a) & 12 & 0,94094 & 1,59090 \\
Coberturas (C) & 3 & $2171,01042^{* *}$ & $132582,57634^{* *}$ \\
Interação A x B & 9 & $118,92333^{* *}$ & $26181,09893^{* *}$ \\
Resíduo (b) & 36 & 0,61455 & 1,92477 \\
Total & 63 & - & - \\
\hline CV \% (LI) & - & 1,58 & 0,35 \\
\hline CV \% (C) & - & 1,28 & 0,38 \\
\hline
\end{tabular}

$\mathrm{FV}=$ Fonte de variação; GL = Grau de liberdade; $\mathrm{CV}=$ Coeficiente de variação; * e ** = Significativo a 5\%, $1 \%$, respectivamente 
Quanto à investigação dos valores médios de produtividade total, observando se a análise de regressão na Figura 1 verifica- se que as lâminas de irrigação e as coberturas no solo, promoveram efeito polinomial, sob a produtividade média da melancia.

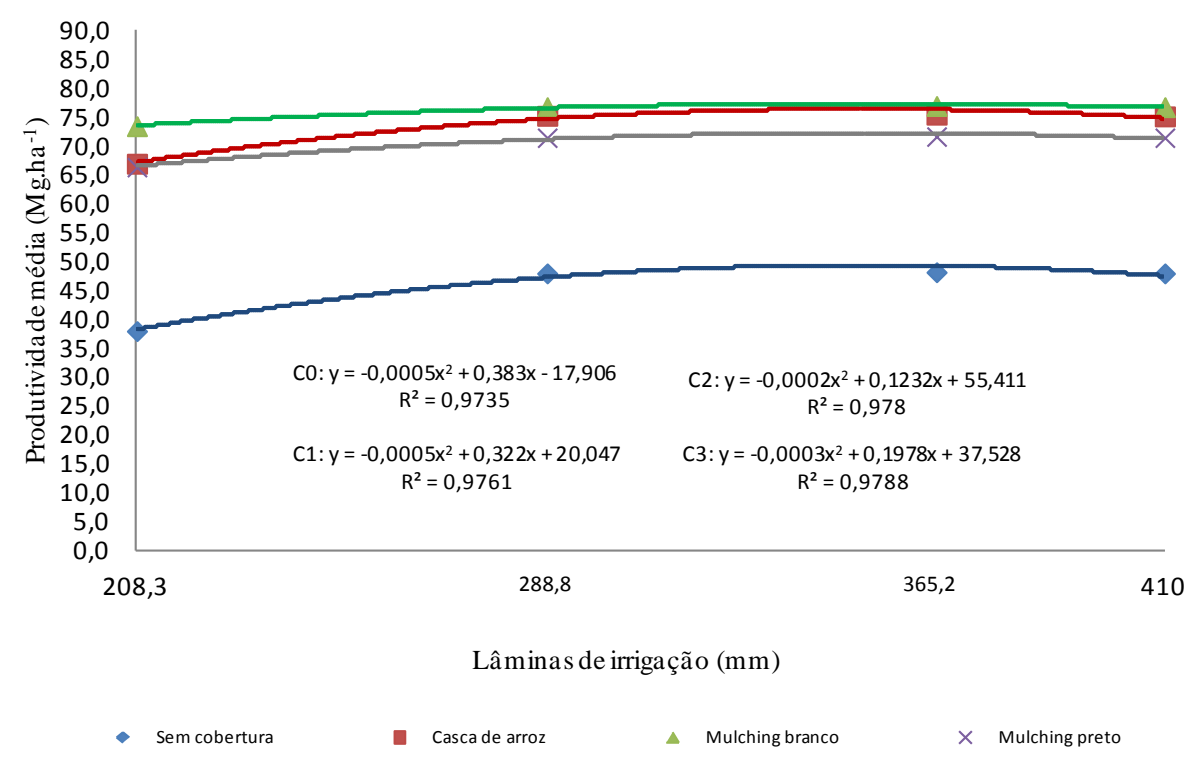

Figura 1. Influência das lâminas de irrigação e condições de cobertura no solo, na produtividade média da cultura da melancia, durante o primeiro ciclo

$\mathrm{Na}$ análise das interações entre as lâminas de irrigação e as coberturas no solo, verifica-se que, até certa condição limiar entre M1 e M4, há um padrão de aumento da produtividade média da melancia, em relação à quantidade de água aplicada, independente do tipo de cobertura no solo. Fato também verificado Oliveira et al. (2012), pois afirmaram que tal comportamento está associado à manutenção de teores adequados de água no solo para a cultura, possibilitando uma maior absorção de água e nutrientes, o que é responsável por uma maior proporção de fotoassimilados translocados das folhas para os órgãos reprodutivos, o que se traduz em aumento de produção.

Na condição de lâmina M1 (365,2 mm) foram verificadas maiores produtividades (77,0 Mg ha-1) em combinação com o solo coberto por "mulching" branco, o que mais uma vez reforça a importância no uso dessa cobertura para a cultura da melancia irrigada. Inclusive Santos et al. (2012) verificaram rendimentos mais elevados com a utilização de cobertura sobre hortaliça. Derivada a equação representativa da produtividade para o solo coberto com tal cobertura, observou-se ponto de produtividade máxima $(74,38 \mathrm{Mg}$ $\mathrm{ha}^{-1}$ ) com lâmina aplicada de $308 \mathrm{~mm}$. Com resultado semelhante Fernandes et al. (2014), analisando as características produtivas da melancia irrigada, chegaram a valores médios de produtividade máxima de $77 \mathrm{Mg} \mathrm{ha}^{-1}$.

Já a menor produtividade, para a mesma lâmina M1, foi observada no solo sem cobertura. Dantas et al. (2011) observaram, estudando a produção e a qualidade do meloeiro cultivado com coberturas plásticas, que a utilização dos mulching plásticos proporcionou um aumento expressivo na produtividade, em relação ao solo nu.

Para as lâminas M4, M2 e M3, as maiores produtividades também foram verificadas no solo coberto por "mulching" branco. Ao se analisar esta variável, tornou-se possível verificar a relação positiva da supracitada cobertura no aumento da produtividade da cultura da melancia, cultivada no DIJA, principalmente em função da retenção de umidade. Fato corroborado por Carvalho et al. (2007), com afirmação de que redução hídrica em certas fases fenológicas 
pode contribuir substancialmente para a diminuição da produtividade da melancia.

Inclusive, analisando os valores obtidos, conclui-se que, independentemente, das coberturas, quanto maior a lâmina aplicada, até certo limite entre M1 e M4, maiores são as produtividades. Inclusive, Santos et al. (2013), investigando a influência de lâminas de irrigação na produção de melancia, constataram que há uma relação direta e positiva entre a lâmina aplicada e a produtividade de melancia

Já com a combinação de menor lâmina e sem cobertura (M3C0) observou - se a menor produtividade, com valor de $38 \mathrm{Mg}$.ha ${ }^{-}$ 1. Esse comportamento, fatalmente, tem explicação fisiológica, pois segundo Azevedo et al. (2005) o déficit hídrico pode causar um decréscimo acentuado nas atividades fisiológicas, principalmente na divisão e no crescimento das células e, em consequência, no crescimento das plantas. Essa deficiência também pode causar o fechamento dos estômatos, diminuindo a concentração intracelular de $\mathrm{CO}_{2}$, gerando um decréscimo na assimilação do mesmo, prejudicando a produção da cultura. Ademais, segundo Taiz e Zeiger (2013) vários fatores podem influenciar o crescimento dos frutos, todavia, o processo de crescimento celular é função da divisão celular e da expansão das células, sendo que, para ocorrência desta, é de grande importância a presença da água.

Na análise dessa variável, com coberturas de "mulching" branco, casca de arroz e "mulching" preto, em ordem decrescente, obtiveram - se os melhores resultados, o que demonstra a vantagem técnica de se utilizar cobertura no solo no cultivo da melancia no DIJA.

Coberturas do solo com filmes de polietileno têm levado ao incremento em crescimento e em produtividade em várias hortaliças (CANTU et al., 2013; MORAIS et al., 2008; LIMA JUNIOR; LOPES, 2009). Somado à eficiência das coberturas, as simulações no ISAREG, com cálculo de irrigação com déficit tornam-se cada vez mais eficazes no manejo da irrigação. Corroborando esse resultado, Dantas et al. (2013) verificaram maiores produtividades de melancia com o uso de "mulching” plástico, em relação ao solo desnudo.

Em relação à eficiência de uso da água, através da análise de regressão (Figura 2) verifica-se que as diferentes lâminas de irrigação, na ausência e na presença de cobertura no solo, proporcionaram efeito polinomial, sob a eficiência de uso da água na cultura da melancia, cultivada no DIJA. Resultado semelhante foi verificado por Oliveira et al.

(2012).

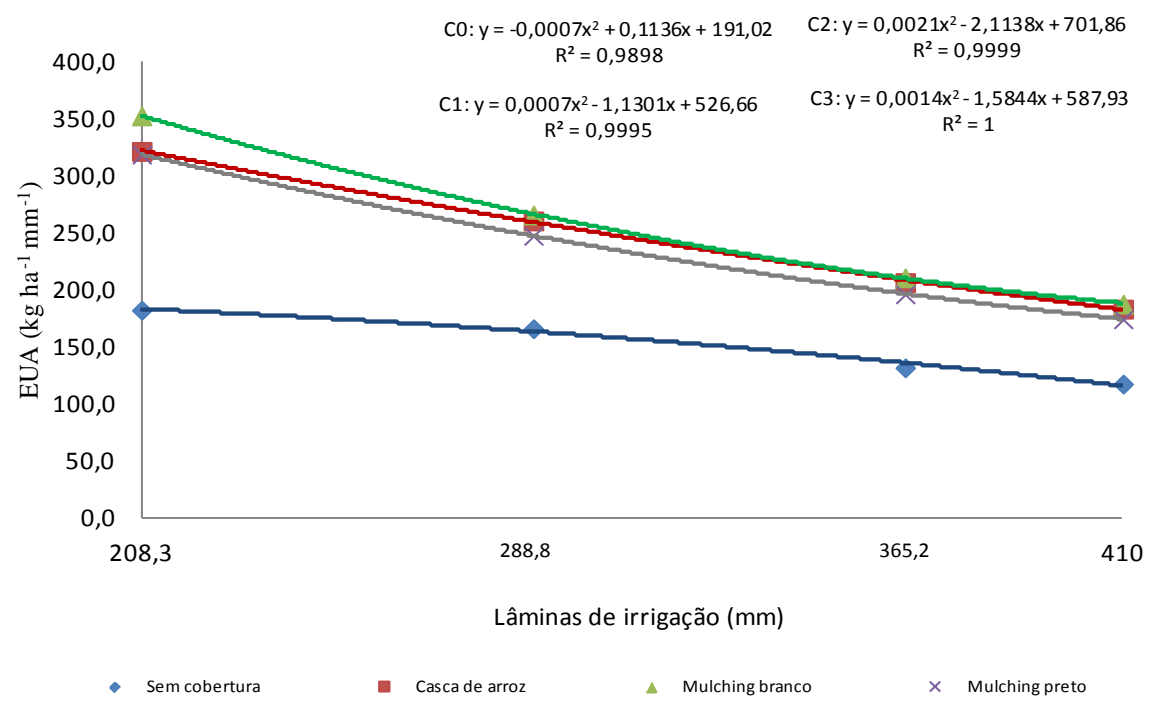

Figura 2. Influência das lâminas de irrigação e condições de cobertura no solo, na eficiência no uso da água para a cultura da melancia cultivada durante o primeiro ciclo 
$\mathrm{Na}$ análise das interações entre as lâminas de irrigação e as coberturas no solo verifica-se que com o aumento da lâmina de água aplicada, houve uma redução na eficiência de uso da água. Inclusive na condição de lâmina M3 foram verificadas maiores eficiências, com valor máximo de $352,85 \mathrm{~kg} \mathrm{ha}^{-1} \mathrm{~mm}^{-1}$ na combinação com o solo coberto por "mulching” branco, o que mais uma vez reforça a importância no uso dessa cobertura para a cultura da melancia irrigada. Já Melo et al. (2010) verificaram EUA máxima de 196,0 $\mathrm{kg} \mathrm{ha}^{-1} \mathrm{~mm}^{-1}$, para a cultura da melancia, com lâmina de $266 \mathrm{~mm}$. Já na combinação M4C0 produziu-se apenas $117,70 \mathrm{~kg} \mathrm{ha}^{-1}$ de melancia, com $1 \mathrm{~mm}$ de água, demonstrou a menor EUA.

A menor eficiência, para a mesma lâmina, foi observada no solo sem cobertura. Para as lâminas M1, M2 e M4, as maiores eficiências foram verificadas nos solos cobertos por "mulching" branco. Ao analisar esta variável tornou-se possível afirmar a relação positiva entre as coberturas e o aumento da EUA para a melancia cultivada no DIJA, pois os maiores valores foram verificados nos experimentos com coberturas, e os menores encontram-se na condição de solo sem cobertura, corroborando a vantagem técnica de se utilizar cobertura no solo do DIJA para a exploração da melancia. Sustentando os resultados verificados na pesquisa, Aragão et al. (2013), investigando as características produtivas da melancia irrigada, com o uso de coberturas no solo, verificaram EUA máxima de 177,2 Kg ha $^{-1} \mathrm{~mm}^{-1}$, na condição de menor lâmina aplicada.

Ademais, Oliveira et al. (2012), analisando a eficiência de uso da água na melancia irrigada, em Pentecoste - CE, verificaram valor máximo de 333,4 $\mathrm{kg} \mathrm{ha}^{-1}$ $\mathrm{mm}^{-1}$, com o uso da menor lâmina experimental de irrigação.

Após a investigação, o modelo ISAREG se mostrou eficiente, como estratégia nas simulações de irrigação com déficit, ficando claro que o manejo modal de irrigação, praticado pelos irrigantes, principalmente quanto ao desperdício de água, não é o ideal, pois, durante todo o ciclo da cultura da melancia ora o irrigante aplica mais água do que a planta necessita, ora menos, mas geral, aplicam demasiadamente, fato esse também verificado por Saraiva et al. (2013) quando fizeram simulações com o modelo ISAREG, visando analisar o manejo da irrigação da cultura da melancia, em Acaraú - CE.

\section{CONCLUSÕES}

Os irrigantes não praticam o manejo correto da irrigação, pois o irrigante aplica, durante todo o ciclo da melancia, mais água do que a indicação de maior lâmina do ISAREG (100\% da CAD); em geral, as plantas irrigadas pela lâmina M1 e sobre solos cobertos por casca de arroz e "mulching" branco demonstraram as maiores produtividades; a maior eficiência de uso da água foi verificada na condição de lâmina M3 com cobertura de "mulching" branco e a menor em M4 com solo sem cobertura.

\section{REFERÊNCIAS}

ALLEN, R. G.; PEREIRA, L. S.; RAES, D.; SMITH, M. Crop evapotranspiration: guidelines for computing crop water requirements. Rome: FAO, 279p. (FAO, Irrigation and Drainage Paper, 56). 1998.

ARAGÃO, C. A.; PINTO, H. C.; QUEIRÓZ, S. O. P.; DANTAS, B. F. Avaliação de melancia cultivada no Vale do Submédio São Francisco sob diferentes manejos de água. Revista SODEBRÁS, v.8, n.91, 2013.

AZEVEDO, B. M. DE; BASTOS, F. G. C.; VIANA, T. V. A.; RÊGO, J. L.; D’ÁVILA, J. H. T. Efeitos de níveis de irrigação na cultura da melancia. Revista Ciência Agronômica, v.36, n.1, p.9-15, 2005.

BERNARDO, S.; SOARES, A. A.; MANTOVANI, E. C. Manual de irrigação. $8^{a}$ ed. Viçosa: Ed. UFV, 2008. 625p. 
CANTU, R. R.; GOTO, R.; JUNGLAUS, R. W.; GONZATTO, R.; CUNHA, A. R. Uso de malhas pigmentadas e mulching em túneis para cultivo de rúcula: efeito no ambiente e nas plantas modelo. Revista Ciência Rural, v.43, n.5, p. 810-815, 2013.

CARVALHO, L. C. C. DE.; BEZERRA, F. M. L.; CARVALHO, M. A. R. DE. Evapotranspiração e coeficientes de cultivo da melancia sem sementes. Revista Ciência Agronômica, Fortaleza, v.39, n.1, p.53-59, 2007.

DANTAS, M. S. M.; GRANGEIRO, L. C.; MEDEIROS, J. F.; CRUZ, C. A.; CUNHA, A. P. A. Rendimento e qualidade de melancia cultivada sob proteção de agrotêxtil combinado com mulching plástico. Revista Brasileira de Engenharia Agrícola e Ambiental, v.17, n.8, p.824-829, 2013.

DANTAS, D. DA. C.; MEDEIROS, J. F. DE.; FREIRE, A. G. Produção e qualidade do meloeiro cultivado com filmes plásticos em respostas à lâmina de irrigação. Revista Ciência Agronômica, v.42, n.3, p.652-661, 2011.

FERNANDES, C. N. V.; AZEVEDO, B. M.; NASCIMENTO NETO, J. R.; MESQUITA, J. B. R.; SARAIVA, K. R. Frequências de fertirrigação nitrogenada e fosfatada na rentabilidade econômica da melancia. Revista Brasileira de Agricultura Irrigada, v.8, n.3, p.270-279, 2014.

FERNANDES, C.N.V.; AZEVEDO, B.M.; NASCIMENTO NETO, J.R.; VIANA, T.V.A.; CÂMPELO, A.R. Desempenho produtivo e econômico da cultura da melancia submetida a diferentes turnos de rega. Irriga, v.19, n.1, p.149-159, 2014.

LIMA JUNIOR, J. A.; LOPES, P. R. A. Avaliação da cobertura do solo e métodos de irrigação na produção de melancia. Semina: Ciências Agrárias, v.30, n.2, p.315-322, 2009.
MELO, A. S. DE; SUASSUNA, J. F.; FERNANDES, P. D.; BRITO, M. E. B.; SUASSUNA, A. F.; AGUIAR NETTO, A. DE O.; Crescimento vegetativo, resistência estomática, eficiência fotossintética e rendimento do fruto da melancieira em diferentes níveis de água. Acta Scientiarum Agronomy, v.32, n.1, p.73-79, 2010.

MIRANDA, F. R. ; OLIVEIRA, J. J. G.; SOUZA, F. Evapotranspiração máxima e coeficientes de cultivo para a cultura da melancia irrigada por gotejamento. Revista Ciência Agronômica, v.35, n.1, p.36-46, 2004.

MORAIS, N. B.; BEZERRA, F. M. L.; MEDEIROS, J. F.; CHAVES, S. W. P. Respostas de plantas de melancia cultivadas sob diferentes níveis de água e de nitrogênio. Revista Ciência Agronômica, v.39, n.3, p.369-377, 2008.

OLIVEIRA, P. G. F.; MOREIRA, O. C.; BRANCO, L. M. C.; COSTA, R. N. T.; DIAS, C. N. Eficiência de uso dos fatores de produção água e potássio na cultura da melancia irrigada com água de reuso. Revista Brasileira de Engenharia Agrícola e Ambiental, v.16, n.2, p.153-158, 2012.

PEREIRA, G. R.; CUELLAR, M. D. Z. Conflitos pela água em tempos de seca no Baixo Jaguaribe, Estado do Ceará. Revista Estudos Avançados, v.29, n.84, p.115-137, 2015.

PEREIRA, L. S. Necessidades de água e métodos de rega. Publicado na Europa e América. 300p. Lisboa-Portugal. 2004.

SANTOS, G. R.; LEÃO, E. U.; GONÇALVES, C. G.; CARDON, C. H. Manejo da adubação potássica e da irrigação no progresso de doenças fúngicas e produtividade da melancia. Horticultura Brasileira, v.31, n.1, p.36-44, 2013. 
SANTOS, S. S.; ESPÍNDOLA, J. A. A.; GUERRA, J. G. M.; LEAL, M. A. A.; RIBEIRO, R. L. D. Produção de cebola orgânica em função do uso de cobertura morta e torta de mamona. Horticultura Brasileira, v.30, p.549-552, 2012.

SARAIVA, K. R.; BEZERRA, F. M. L.;
SOUZA, F.; CAMBOIM NETO, L. F. Aplicação do "ISAREG" no manejo da irrigação na cultura da melancia no Baixo Acaraú, Ceará. Revista Ciência Agronômica, v.44, n.1, p.53-60, 2013.

TAIZ, L.; ZEIGER, E. Fisiologia vegetal. 5.ed. Porto Alegre: Artmed, 2013. 918p. 